\title{
PerCursos
}

\section{As políticas culturais e as culturas políticas em Santa Catarina ${ }^{1}$}

\begin{abstract}
Resumo
O presente artigo discute os meandros das lutas políticas no setor cultural em Santa Catarina, articuladas entre a segunda metade da década de 1980 (durante o processo de redemocratização) e o final da primeira gestão do governo de João Raimundo Colombo (DEM/PSD), em 2014; são analisadas as estruturas burocráticas de cultura no estado a partir do impacto das ações federais realizadas no período. A participação da sociedade civil nesse processo será destacada nas ações de coletivos organizados por sujeitos do setor cultural, interessados em ampliar o espaço público e confrontar uma cultura política conservadora instalada nos espaços de poder.
\end{abstract}

Palavras-chave: Política Cultural. Democratização. Cidadania Cultural. Santa Catarina.

\section{Luciana Mendes dos Santos \\ Mestra em História pela}

Universidade do Estado de Santa

Catarina - UDESC. Doutoranda

em História pela Universidade do

Estado de Santa Catarina -

UDESC.

Brasil

lucianadsmendes@gmail.com

\section{Para citar este artigo:}

SANTOS, Luciana Mendes dos. As políticas culturais e as culturas políticas em Santa Catarina. Revista PerCursos, Florianópolis, v. 20, n.42, p. 199 - 224, jan./abr. 2019.

DOI: $10.5965 / 1984724620422019199$

http://dx.doi.org/10.5965/1984724620422019199

\footnotetext{
${ }^{1}$ O presente trabalho foi realizado com apoio da Coordenação de Aperfeiçoamento de Pessoal de Nível Superior - Brasil (CAPES).
} 


\title{
Cultural Politics and political cultures in Santa Catarina
}

\begin{abstract}
This article discusses the intricacies of political struggles in the cultural sector of Santa Catarina that were articulated between the second half of the 1980's (during the process of redemocratization) and the end of the first administration of the government of João Raimundo Colombo (DEM / PSD) in 2014; the bureaucratic structures of the state's culture are analyzed based on the impact of the federal actions carried out in the period. The participation of civil society in this process will be highlighted in the actions of groups that were organized by cultural sector's agents interested in expanding the public space and confronting a conservative political culture installed in the spaces of power.
\end{abstract}

Keywords: Cultural Politics. Democratization. Cultural Citizenship. Santa Catarina (Brazil). 


\section{Introdução}

O presente artigo busca analisar o processo de formação do setor cultural na esfera estatal em Santa Catarina, no período entre a segunda metade da década de 1980, durante o processo de redemocratização, e o final da primeira gestão do governo de João Raimundo Colombo (DEM/PSD), em 2014. Esse processo foi estruturado em intenso debate com as políticas desenvolvidas pelo governo federal, passando por fases de sintonia nas ações desenvolvidas pelos governos (ocasionadas pela coesão entre as culturas políticas dominantes nas esferas federal e estadual, em determinados ciclos de poder) e por momentos de tensão entre os objetivos das políticas federais e os interesses dos agentes envolvidos no setor cultural estadual. Observando esse processo de formação do setor cultural estatal em Santa Catarina, percebemos a influência do conservadorismo e do autoritarismo na constituição dos programas e projetos para a área, com base em práticas políticas que demarcaram disputas pelo poder.

O cenário apresentado torna-se mais significativo na história política de Santa Catarina por conta da alternância de partidos e pelos grupos políticos ideologicamente pouco distintos no governo catarinense, representantes de uma elite política conservadora, fortalecida durante o século XX (MIRANDA, 2012). Segundo Ricardo Duwe (2016), o estabelecimento dessa elite política, formada por famílias como a Konder Bornhausen, assentava-se em uma cultura política marcada pelos seguintes fatores:

(...) clientelismo, personalismo e patriarcalismo; uma crença em comum no estado federativo pautado em uma democracia liberal; na percepção de que o desenvolvimento econômico do Estado deve voltar-se ao progresso do setor privado; e na ideia de que estes políticos tradicionais eram predestinados à vida pública enquanto representantes políticos da sociedade catarinense. (DUWE, 2016, p. 33)

No recorte abordado, mesmo nos períodos em que as famílias tradicionais de Santa Catarina ${ }^{2}$ não se encontravam na esfera executiva ${ }^{3}$, a influência política desses

\footnotetext{
${ }^{2}$ Na história política de Santa Catarina, algumas famílias tiveram uma presença constante nas estruturas de poder. Podemos destacar a família Salles, a família Hülse, a família Ramos, a família Amin e a já citada
} 
grupos nas instituições e políticas públicas estaduais foi uma constante, fazendo com que os projetos para a cultura acompanhassem algumas dessas características tão arraigadas nas estruturas burocráticas, apesar das alternâncias de governo. Este trabalho irá discutir como tais disputas influenciaram a constituição do setor cultural estatal em Santa Catarina, destacando os espaços de participação da sociedade civil e o alcance das culturas políticas dominantes neste processo.

A noção de cultura política é empregada neste artigo na acepção de Serge Berstein (1998), ou seja, esta constitui um conjunto coerente de elementos, como códigos ou conjuntos de referências formalizados no meio político - no partido, na família, na tradição e na sociedade - que permitem definir uma forma de identidade do indivíduo. O autor expõe que, para efetuar a construção de uma cultura política como um conjunto homogêneo, diversos fatores incorrem nesse processo: uma base filosófica ou doutrinal, uma visão comum de passado histórico, em que se atribui valor aos acontecimentos através de suas narrativas; uma perspectiva de organização estatal e institucional, elaborada a partir de sua visão histórica ou filosófica; uma projeção de sociedade ideal e um discurso codificado permeado por um vocabulário portador de significação (BERSTEIN, 1998, p. 351).

A elaboração dessas culturas políticas nos auxilia a compreender as motivações dos atos dos homens em diferentes temporalidades, por referência ao sistema de valores, normas e crenças que partilham, em função de sua leitura do passado, das suas aspirações para o futuro, das suas representações da sociedade. No interior de uma nação, há uma diversidade de culturas políticas que possuem áreas nas quais a pluralidade dos valores converge em uma unidade. O processo de formação das culturas políticas, segundo o autor, não pode ser visto como fenômeno imóvel, e sim como processo de construção histórica e de constante transmutação, no qual uma ideia nova

família Konder Bornhausen como manifestação desse processo, tendo em vista que os seus membros assumiram cargos, tanto no executivo quanto no legislativo catarinense, e que essas famílias continuam atuando na cena política estadual e federal.

3 Destacam-se os períodos de gestão dos governadores Luiz Henrique da Silveira (2003-2010) e Raimundo Colombo (2011-2018). 
demanda tempo para se consolidar como conjunto compartilhado de representações normativas:

Noutros termos, é necessário o espaço de pelo menos duas gerações para que uma ideia nova, que traz uma resposta baseada nos problemas da sociedade, penetre nos espíritos sob a forma de um conjunto de representações de caráter normativo e acabe por surgir como evidente a um grupo importante de cidadãos. (BERSTEIN, 1998, p. 356)

Os canais para a consolidação da cultura política perpassam canais de socialização política como a família, a escola, os grupos sociais nos quais o cidadão está inserido e os canais de comunicação: "a ação é variada, por vezes contraditória, e é a composição de influências diversas que acaba por dar ao homem uma cultura política, a qual é mais uma resultante do que uma mensagem unívoca" (BERSTEIN, 1998, p. 357).

Para Rodrigo Patto Sá Motta (2013), a virada culturalista que ocorria nas ciências humanas no final do século $X X$, influenciou historiadores interessados em renovar 0 enfoque da história política a reencontrar e reconstruir a categoria cultura política, reconhecendo a influência da dimensão cultural nas decisões e ações políticas:

A perspectiva culturalista, portanto, a aplicação do conceito de cultura política, supõe a convicção de que os homens agem também movidos por paixões e sentimentos, como medo, ódio e esperança; são mobilizados por meio de representações e imaginários que constroem mitos e heróis exemplares, bem como inimigos odientos; e tomam decisões por influência de valores construídos em torno da família, nação ou religião. (MOTTA, 2013, p. 17)

Para o autor, a cultura política é um conjunto de valores, tradições, práticas e representações políticas partilhadas por um grupo específico, expressando uma identidade coletiva e fornecendo leituras comuns do passado e inspiração para projetos políticos de futuro (MOTTA, 2009, p. 21). Essa conceituação, segundo Motta, pode ser utilizada tanto para conjuntos nacionais, como a cultura política brasileira, quanto para projetos específicos, como o comunismo, o liberalismo e o conservadorismo. Cada uma 
dessas culturas políticas compartilha perspectivas do passado e expectativas para o futuro, criando projetos a partir desses valores internalizados. Esse conceito será relacionado ao de projeto político, definido por Dagnino, Olvera e Panfichi como um “conjunto de crenças, interesses, concepções de mundo, representações do que deve ser a vida em sociedade, que orientam a ação política dos diferentes sujeitos" (2006, p. 38), em que a política é um terreno estruturado por escolhas expressas nas ações dos sujeitos, orientadas por esses projetos políticos e que se encontram em uma relação conflitiva, seja entre os diferentes projetos ou com as estruturas disponíveis para a sua efetivação.

\section{Invenção e transformação das estruturas culturais no Estado de Santa} Catarina

A formação de uma estrutura cultural no Estado de Santa Catarina tem seu início em 1956, quando passou a figurar como elemento político na Diretoria de Cultura da Secretaria de Estado dos Negócios da Educação e Cultura, criada por Jorge Lacerda; foi fortalecida em 1961, quando as diretrizes do Conselho Estadual foram fixadas pelo governo federal. Em 1979, o governo de Antônio Carlos Konder Reis criou a Secretaria de Cultura, Esporte e Turismo e a Fundação Catarinense de Cultura (FCC), responsável por executar políticas de desenvolvimento cultural formuladas pela Secretaria, estrutura mantida nas gestões posteriores de Jorge Bornhausen (1979-1982) e Esperidião Amin (1983-1987). Contudo, foi na gestão de Pedro Ivo e Casildo Maldaner (1987-1990) que os horizontes da Cultura começam a se expandir teoricamente, ao mesmo tempo em que se percebe uma sintonia com o projeto neoliberal desenvolvido pelo governo federal.

A renovação do pensamento sobre as políticas culturais perpassa as análises realizadas pelas Ciências Sociais e a Antropologia, que modificaram sua visão sobre o assunto, criando zooms no cotidiano para destacar seus detalhes.

Para Brunner (1988), há duas dimensões da cultura que podem influenciar o alcance e a amplitude das ações promovidas: a dimensão sociológica de cultura, que visa à produção especializada e culta, voltada a um determinado tipo de público, que possa 
entender os sentidos elaborados pelos artistas, criando condições para a especialização e canais específicos de comunicação da produção; e a dimensão antropológica, que reflete a cultura como produto da interação social dos indivíduos, âmbito em que se criam os valores, as formas de pensar e sentir e em que são elaboradas as suas identidades e os seus próprios sentidos. O que determina essas construções culturais são as origens regionais, os interesses profissionais, econômicos, esportivos e culturais, o gênero, a idade e a posição social do indivíduo. É possível perceber que a dimensão antropológica de cultura é menos restritiva, se comparada à dimensão sociológica, compreendendo esses pequenos mundos elaborados e produzidos pelo ser humano em seu universo privado como formadores da cultura, com um olhar atento aos microcircuitos do cotidiano4.

Em uma entrevista realizada em 1988 para o periódico Cultura ${ }^{5}$, a secretária da Cultura e do Esporte do Estado de Santa Catarina entre os anos de 1987 e 1991, Zuleika Mussi Lenzi, afirmava a importância das mudanças realizadas pelo Ministério da Cultura (MinC), desde sua criação, para a gestão da Cultura no Estado de Santa Catarina: "Apesar de existir há apenas três anos, o Ministério da Cultura está tendo um papel muito importante no entendimento da cultura num sentido mais amplo, compreendendo todo fazer cultural e não apenas a atividade artística" (LENZI, 1988, p. 3). Nessa entrevista, a socióloga, ex-vereadora e professora da Universidade Federal de Santa Catarina, empenhava-se em sintonizar sua narrativa, as diretrizes definidas para as ações da Secretaria e das instituições que Ihe eram subordinadas com o projeto definido pelo MinC; este último pretendia preservar e desenvolver o patrimônio cultural ligado ao cotidiano da população, estimular a produção cultural sem o dirigismo estatal, apoiar a

\footnotetext{
${ }^{4}$ Vale ressaltar que serão adotadas neste trabalho as categorias de cultura antropológica e de cultura sociológica de Brunner (1998), com o entendimento de que esses conceitos não atendem à diversidade de significados que a cultura possui para os campos da Sociologia e da Antropologia, visando facilitar a análise e identificação das características das políticas implementadas em Santa Catarina.

${ }^{5}$ O primeiro número do Jornal Cultura, editado pela Secretaria da Cultura e do Esporte e pela Fundação Catarinense de Cultura, foi publicado em setembro de 1988; sua última edição é de 1991. A proposta inicial era que fosse publicado bimensalmente e divulgado amplamente nos espaços de cultura de Santa Catarina; entretanto, durante os seus três anos de existência, apenas quatro volumes foram publicados. Eles estão disponíveis para consulta no acervo da Hemeroteca Digital Catarinense (<www.hemeroteca.ciasc.sc.gov.br/>. Acesso em: 23 jul. 2018). A edição número "o", selecionada para análise neste artigo, conta com 12 páginas, divididas em seis seções.
} 
atividade cultural diversa e estimular a difusão e o intercâmbio cultural, de acordo com o ministro Celso Furtado, em 1987. Com o título de "Novos rumos para a Cultura", a entrevista buscou promover a visão de uma Secretaria interessada nas ações de descentralização do governo para a Cultura - envolvendo outros setores da sociedade e favorecendo a interiorização dos recursos para municípios afastados da capital; na promoção da identidade catarinense baseada na diversidade cultural do estado, no incentivo público e privado para produções culturais e na organização administrativa dos órgãos do estado. É um conceito de cultura amplo, que articula os significados do cotidiano às políticas promovidas em nível estadual.

Utilizando esse espaço de legitimação de sua gestão, Lenzi (1988) expôs que os rumos das ações executadas impulsionaram uma política mais abrangente em Santa Catarina, com o uso dos recursos financeiros disponibilizados por meio de editais, que atendiam aos grupos de dança e de teatro, aos grupos folclóricos, aos artistas plásticos, ao circo, aos projetos de formação artística em andamento e às bandas de música, contrastando com a gestão anterior de Esperidião Amin que, segundo a secretária, beneficiava somente a música erudita e o balé clássico, atividades voltadas para um público pequeno e elitista (LENZI, 1988, p. 3). Também ressaltou a importância da participação do setor privado no fomento de ações culturais, afirmando que, com uma receita para a Cultura que não atingia $1 \%$ do orçamento do estado, algumas metas foram alcançadas devido aos projetos financiados com recursos de instituições privadas. Reconheceu: “é preciso considerar que, nos anos mais recentes, a iniciativa particular passou a explorar as oportunidades de investimento e faturamento no campo da produção cultural, visando tanto ao retorno financeiro, como ao marketing cultural" (LENZI, 1988, p. 3).

O periódico Cultura, aqui particularmente destacado, possibilitou um espaço público de discussão e de críticas, apesar de seus vínculos oficiais, pois era publicado pela Secretaria da Cultura e do Esporte e pela FCC. Era uma iniciativa surgida no âmbito do primeiro governo eleito pelo voto direto em Santa Catarina ligado a um partido que fizera oposição à ditadura civil-militar (no caso, o PMDB - Partido do Movimento Democrático Brasileiro), e que, àquela altura, ainda conseguia mobilizar uma parte dos segmentos 
ligados às atividades culturais e intelectuais no estado. O fato de o mesmo partido estar na gestão federal facilitava essa singularidade nas ações entre os entes da federação, e inseria o setor cultural em disputas que transbordavam os limites de suas ações, por conta da rivalidade entre os grupos políticos de Santa Catarina. O projeto realizado pela Secretaria do Estado da Cultura e do Esporte e pela FCC tinha o intuito de estabelecer um espaço de debate dos agentes culturais do estado de Santa Catarina, um meio de divulgação das ações culturais desenvolvidas, principalmente pelas instâncias estatais, e das manifestações culturais e as produções feitas pelos diversos grupos sociais em Santa Catarina.

Na edição número “o” de Cultura (1988, p. 6-7), na seção “Os produtores e a relação Estado/cultura", artistas, escritores, cineastas, diretores de teatro, jornalistas e funcionários de instituições culturais das cidades de Florianópolis, Joinville, Tubarão, Blumenau e São Francisco do Sul apresentaram diferentes pontos de vista sobre a interferência do governo estadual na Cultura, apoiando suas ações, comparando aquela gestão com as anteriores e exercendo pressões políticas.

Os contrastes entre os agentes culturais são fortes, principalmente por se tratar de indivíduos que já possuíam uma presença consolidada no cenário cultural catarinense. Como no caso de Haroldo Silva, diretor de teatro de Tubarão, que fez elogios à ação do governo estadual e defendeu que os subsídios deveriam ser oferecidos aos grupos que já possuíam uma produção consolidada: “entendo que os grupos de teatro precisam mostrar competência para depois reclamar subsídios oficiais" (OS PRODUTORES... 1988, p. 7). Já José Roberto Rodrigues, jornalista de Joinville, sustentava a participação mínima do Estado: “a interferência do Estado deve ser mínima, as preocupações fundamentais deveriam ser com a produção local, a troca de experiências através de cursos e debates e a devolução à comunidade daquilo que o poder público recolheu" (OS PRODUTORES... 1988, p. 7). Silvio Orlando Borges, diretor de teatro de Joinville, alegava que o Estado deveria buscar o desenvolvimento cultural: "a função básica do Estado é alimentar as manifestações das comunidades. Ele precisa estar junto da população para levantar suas carências, necessidades e interesse, e depois agir, investindo em práticas que estimulem o seu desenvolvimento cultural" (OS PRODUTORES... 1988, p. 7). 
As críticas mais diretas aos órgãos responsáveis pela publicação também conquistaram seu espaço, como a de Luís Moreira, músico de Florianópolis que acreditava que a administração do período estava fazendo um trabalho inferior à gestão anterior, eleita em 1982 pelo partido de sustentação da ditadura (então denominado de PDS Partido Democrático Social): “a atual administração vai mal, tem gente errada nos postos errados, falta contato com os artistas e as pessoas da área, da Secretária aos funcionários, não têm vivência artística. Há pouco dinheiro e muita elitização e empreguismo" (OS PRODUTORES... 1988, p. 6). O músico também relatou que o governo anterior garantia o aluguel e o transporte de equipamentos de som, enquanto o governo vigente não estimulava o contato com os artistas.

Entre os catorze agentes de cultura chamados para apresentar sua visão na seção "Os produtores e a relação Estado/cultura", três citaram problemas como o empreguismo e o paternalismo nas estruturas estatais, reivindicando sua eliminação, e outros sete apoiavam as medidas do governo, como a interiorização dos recursos para a Cultura e o apoio a projetos para o cinema e comunidades.

Encontramos, em alguns outros trechos da publicação, referências a possíveis apadrinhados, inconformados com a nova configuração da política cultural, que tencionava realizar uma interiorização dos recursos e ampliar o acesso aos financiamentos da cultura em projetos até então não beneficiados. Na entrevista mencionada, Lenzi (1988, p. 3) fez uma crítica aos governos anteriores, que a seu ver sustentaram artistas e intelectuais desqualificados, e aos artistas que esperavam uma continuidade desse sistema, alertando que essa expectativa seria frustrada com as novas exigências feitas pelo governo para a obtenção de recursos.

A relação entre Estado, política e cultura aparece no impresso Cultura com a construção de uma fronteira, ao mesmo tempo tensa e flexível, em relação aos interesses dos agentes envolvidos. Tensa por conta da disputa política nos meandros da área de Cultura, como uma concorrência constante por recursos, espaço e poder político; e flexível pelas políticas voltadas a atender diferentes interesses no âmbito das atividades culturais e na ampliação do acesso aos recursos para os grupos envolvidos. Sabemos que uma opinião apresentada no periódico Cultura não estava livre de influências políticas, 
tendo em vista que o jornal era produto de um conjunto de indivíduos congregados no Conselho Editorial e de colaboradores ligados às instituições culturais da administração estadual que, como ocorre em outras publicações dessa natureza, pretendiam difundir suas ideias, crenças e projetos por meio da palavra escrita (LUCA, 2006). A tensão presente nessa seção demonstra que o espaço cultural não estava livre de enfrentamentos e disputas, e que diferentes projetos eram apresentados com vistas à obtenção de influência política.

Democratização cultural, maior disponibilidade de recursos por grupos antes excluídos do processo de desenvolvimento cultural, descentralização das ações do campo, busca de apoio de empresas para complementar os recursos escassos fornecidos pelo Estado e aumentar a oferta de produtos culturais: o Estado e a Cultura se relacionaram pretendendo garantir o acesso aos bens culturais sem dirigismo, seja estatal ou mercadológico das ações culturais que, segundo os editores do periódico, era considerado um dos maiores perigos no meio cultural durante o período de redemocratização. As diretrizes do MinC atingiam as ações do Estado de Santa Catarina, influenciando as políticas promovidas na Secretaria da Cultura e do Desporto. Salientamos que, assim como o periódico Cultura, a política cultural não é um espaço neutro, uma vez que as ações nesse âmbito são orientadas conforme correlações de força entre grupos articulados, formando terrenos de disputas. As políticas compreendem relações sociais, sendo construídas como parte de conflitos entre os grupos envolvidos que, naquele momento, ainda viviam sob as experiências e expectativas suscitadas pela Nova República. Segundo Dagnino (2005), no âmbito da redemocratização, surgiram oportunidades para construir espaços de participação da sociedade civil nas decisões sobre políticas públicas, por meio de diferentes tentativas de construção de esferas públicas mediadoras, como consta nos objetivos expostos no editorial do número "o" de Cultura: pretendia-se criar um espaço de relacionamento entre os municípios, as instituições culturais, os produtores e suas manifestações, propondo "a troca de informações".

Nas ações voltadas para Santa Catarina, materializadas em editais, concursos e na reestruturação das instituições ligadas à Secretaria do Estado da Cultura e do Esporte, 
percebemos o uso de conceitos relativos à cultura como um direito e como um elemento diverso, a ser promovido, divulgado e conservado pelo Estado. Entretanto, a amplitude dos conceitos nem sempre alcançou a extensão de seus objetivos, deixando em segundo plano a construção de uma política cultural efetiva e a inserção dos diversos atores sociais e de suas lutas políticas por representatividade nas ações culturais pela administração estadual.

Na década de 1990, as políticas para o setor no governo estadual serão novamente inseridas no processo de mercantilização da cultura, por meio de um projeto político neoliberal desenvolvido pela gestão de Vilson Kleinübing e Konder Reis (1991-1994), do Partido da Frente Liberal (PFL). A cultura como fator de desenvolvimento econômico deveria ser ajustada aos padrões do mercado; suas ações seriam voltadas à cultura especializada, que gera margem de lucro e se destaca nas relações com a iniciativa privada, conforme compreendida no plano de governo, o Plano SIM - Saúde, Instrução e Moradia, para o qual "as artes desencadeiam o desenvolvimento econômico, estimulam projetos de imóveis comerciais e residenciais, incentivam o turismo e atraem novas empresas" (KLEINÜBING; KONDER-REIS, 1991, p. 6). Restringia-se a cultura a expressões consagradas, como as artes plásticas, a literatura e o patrimônio histórico, sem prever ações para manifestações culturais de povos que não diziam respeito à memória de imigração europeia:

Caracterizando um foco patrimonialista, o Plano baseia-se na premissa de que é preciso realizar "estudo aprofundado da cultura natural existente nas diferentes regiões", "fomentar essas expressões" e "apoiar iniciativas que correspondam à manifestação cultural própria da região" (KLEINÜBING; KONDER-REIS, 1991, p. 6/13), numa clara demonstração de que não acredita na possibilidade da cultura se manifestar fora de fronteiras bem definidas, que no Plano são estabelecidas como sendo das "manifestações culturais ligadas às grandes correntes formadoras do povo e da cultura catarinense", definidas como pertencentes às correntes "luso-cabocla, indígena, africana, alemã, italiana e gauchesca" (KLEINÜBING; KONDER-REIS, 1991, p. 6/11). Estas fronteiras tornam-se ainda mais restritivas quando o Plano só especifica ações para quatro dessas "culturas": a açoriana, a italiana, a alemã e a polonesa. Esta orientação por valores que privilegiam as formas culturais consideradas autóctones aproxima-se do tipo nacionalista. (OLIVEIRA, 2007, p. 89-90) 
Parte do projeto político liberal se faz, também, pela redução das estruturas estatais (DAGNINO, 2004), e a Cultura, em conjunto com a área de Esporte, tornou-se responsabilidade da Secretaria de Educação. A FCC passou a abrigar em seu escopo a Diretoria de Patrimônio, em 1992, limitando sua esfera de ação à difusão das artes entendidas como cultura especializada, e à salvaguarda do patrimônio cultural, circunscrevendo sua ação nos limites da dimensão sociológica de cultura.

Durante a gestão de Paulo Afonso Vieira (1995-1998), do PMDB, o setor cultural foi objeto de reestruturações, com a criação e a extinção da Secretaria de Cultura e Comunicação Social (SECCOM), a retirada do poder deliberativo do Conselho Estadual de Cultura (CEC), vinculando o órgão à FCC com função consultiva e fiscalizadora da política de ação cultural estatal através da Lei n. 10.308/96; e a criação da Lei Estadual de Incentivo à Cultura (Lei n. 10.929 de 23 de setembro de 1998), estabelecendo o Mecenato Estadual de Incentivo à Cultura (MEIC) e o Fundo Estadual de Incentivo à Cultura (FEIC), no intuito de reafirmar o compromisso de seu governo de mobilizar a sociedade civil e as entidades privadas, estimulando o marketing institucional. Entretanto, essa gestão ficou marcada também por obras inacabadas, atraso no pagamento de servidores públicos e projetos não finalizados. Por conta desse cenário, apenas na gestão seguinte, de Esperidião Amin (1999-2002), do Partido Progressista Brasileiro (PPB), a política de incentivo fiscal começou a ser aplicada, não tendo o grande alcance das poucas edições do edital.

\section{Política pública e sociedade civil: espaços de confronto e construção}

Os períodos relativos aos dois mandatos de Luiz Henrique da Silveira (2003-2010), do PMDB, e ao mandato de João Raimundo Colombo (2011-2014), que iniciou sua gestão no Partido Democratas (DEM) e depois, em maio de 2011, migrou para o Partido Social Democrático (PSD), demonstram a estabilidade na manutenção de projetos políticos conservadores para Santa Catarina nos processos eleitorais que, no século XX, se perpetuaram na cena política estadual, com períodos de domínio absoluto do poder (CARREIRÃO, 1988, p. 248). A gestão do setor cultural na administração estadual, 
entretanto, irá reafirmar as inconstâncias no processo de formação das políticas culturais no Brasil, discutidas por Rubim (2007), sendo demarcadas pela ausência, pelo autoritarismo e pela instabilidade, como uma triste tradição que impede um desenvolvimento contínuo das potencialidades do setor.

A formulação de estruturas burocráticas para o setor foi cercada pela inconstância nesse início de século: a Secretaria de Estado de Turismo, Cultura e Esporte foi ocupada por oito secretários diferentes, e a FCC, no mesmo período, teve nove nomes em sua direção ou em sua presidência. A intensa movimentação da sociedade civil demarcou o período, enquanto a reestruturação de órgãos estaduais de Cultura, a reformulação do sistema estadual de financiamento da cultura e a implementação de acordos e convênios com o governo federal, dos quais a principal ação configura-se nos Pontos de Cultura, contribuíram para demandas em torno da renovação do setor cultural do estado.

A primeira gestão de Luiz Henrique da Silveira (2003-2006) reassumiu o discurso de descentralização do Estado. Os projetos políticos para a Cultura foram demarcados pela visão do lazer como ócio criativo, ideia desenvolvida por Domenico De Masi (2000), segundo a qual as barreiras entre o lazer, o trabalho e o estudo seriam removidas em prol de um desenvolvimento criativo da sociedade, tomando o "lazer como integração entre turismo, cultura e esporte, assim como integração dessas áreas com as áreas sociais e da educação" (SANTA CATARINA, 2009, s.p.). Essa abordagem gerou a necessidade da criação de uma nova pasta na estrutura burocrática: a Secretaria da Organização do Lazer - SOL, responsável pelas áreas do Turismo, da Cultura, do Desporto e do Lazer. Na lei referente à sua criação, a Lei Complementar n. 243, de 30 de janeiro de 2003, dentre as dez competências relacionadas no artigo 52, seis são relativas à promoção do turismo no estado, não havendo nenhuma competência específica para o setor cultural, mantidas na FCC, que teria como função:

I - executar a política de apoio à cultura; II - formular, coordenar e executar programas de incentivo às manifestações artísticas; III preservar os valores culturais e manifestações artísticas; IV - incentivar a produção e a divulgação de eventos culturais; $V$ - estimular a pesquisa e 0 estudo relacionados à arte e à cultura; $\mathrm{VI}$ - apoiar as instituições públicas 
e privadas, que visem o desenvolvimento artístico e cultural; e VII promover a integração da comunidade, através da mobilização das escolas, associações, centros e clubes, a áreas de animação cultural. (SANTA CATARINA, 2003, s.p.)

Para organizar a ação da Secretaria, foi criado o Plano de Desenvolvimento do Lazer Integrado (PDIL), lançado em 2006 e aprovado somente em 2009, como Plano Estadual da Cultura, do Turismo e do Desporto do Estado de Santa Catarina (PDIL). Nesse plano, os projetos dos subprogramas descritos no Programa de Desenvolvimento da Cultura deveriam compreender: a organização do mercado cultural, pensando a cultura como segmento econômico; a criação da Rede Integrada de Cultura de Santa Catarina (RIC/SC), envolvendo ações para o resgate e a difusão do patrimônio imaterial do estado; a promoção da difusão da cultura através de eventos para os segmentos de artes visuais e artesanato, música, dança, teatro e audiovisual, estimulando a promoção de feira de livro e de ações culturais em espaços públicos, incentivando a formação dos agentes e apoiando "os estudos, pesquisas e ações na área da antropologia cultural catarinense" (SANTA CATARINA, 2009, s.p.); a valorização e proteção do patrimônio cultural material.

Para regulamentar o processo de renúncia fiscal, seu governo extinguiu a Lei de Incentivo à Cultura elaborada em 1998, na gestão de Paulo Afonso Vieira, e instituiu o Sistema Estadual de Incentivo à Cultura, ao Turismo e ao Esporte (SEITEC), pela Lei n. 13.336, de 08 de março de 2005, integrando as três áreas de ação presentes no PDIL, no qual cada setor teria seu próprio fundo, e o da cultura era o Fundo Estadual de Incentivo à Cultura (FUNCULTURAL). Em seu projeto de descentralização de serviços e de algumas decisões administrativas, o governo criou trinta secretarias de Estado de Desenvolvimento Regional (SDRs), buscando diminuir as desigualdades existentes entre as regiões do estado e garantir a eficiência dos serviços públicos. No processo de seleção do edital do programa federal Mais Cultura, os vínculos com demandas das SDR's foram utilizados como critério na avaliação de mérito, na tentativa de ampliar a distribuição dos espaços culturais em Santa Catarina.

Em um estado em que as narrativas políticas e sociais predominantes, com viés conservador, remontam a discursos em que o trabalho é valorizado como se fizesse parte 
das características étnicas da população, tomado como meio para obter o progresso e empreender o acúmulo de capital, parte dessa grande arena formadora da sociedade civil serviu de palco para questionamentos sobre uma Secretaria dedicada ao ócio, bem como sobre o conceito de lazer como integrador das áreas de esporte, cultura e turismo, limitando-os ao entretenimento (DELLAGNELO; PEREZ, 2015). Diante da insatisfação, Luiz Henrique da Silveira promoveu uma revisão no setor durante seu segundo mandato (2007-2010) já que, além do nome da Secretaria ter se tornando inconveniente, a pasta não apresentou os resultados esperados:

Em 2003 a Secretaria era nova, sem funcionários próprios, equipes pouco estruturadas e um relacionamento precário com as secretarias regionais. Todo esse quadro institucional parece não ter facilitado a concretização de ações significativas no campo do chamado lazer integrado como pretendia o governo. (DELLAGNELO; PEREZ; 2015, p. 274)

A Secretaria é reestruturada e renomeada em 2006 como Secretaria do Turismo, Cultura e Esporte, mas, assim como o Plano Estadual da Cultura, do Turismo e do Desporto do Estado de Santa Catarina, que manteve a sigla PDIL, também manteria sua sigla (SOL), reiterando a posição do governo no destaque ao lazer. As estruturas da FCC foram reduzidas nesse processo, passando quase à sua extinção pela reforma administrativa iniciada em 2005, que autorizou o repasse de verbas do Estado às Organizações Sociais $(\mathrm{OS})^{6}$. As intenções do novo governo quanto à $\mathrm{FCC}$ foram limitadas por conta da mobilização de segmentos organizados da sociedade civil, coordenada pela recém-criada Frente em Defesa da Cultura Catarinense, que se opôs ao encerramento de suas atividades, tendo em vista que o Estado não possuía nenhuma proposta de entidade reguladora do setor que ampliasse a participação social. O CEC foi integrado à SOL e houve a criação de um Comitê Gestor do FUNCULTURAL, responsável pela fiscalização das decisões do Conselho em relação ao SEITEC, composto por três integrantes - o secretário da SOL, o presidente da FCC e o representante da CEC, reduzindo, na prática, "o poder de decisão do Conselho, fazendo com que o critério político prevalecesse nas

\footnotetext{
${ }^{6}$ As OS são entidades criadas por vontade do poder público, que concede a elas a gestão de certo patrimônio público e o direito a desenvolverem funções que antes eram do Estado (MARTINS, 2005).
} 
decisões de distribuição de recursos na área da cultura no estado" (DELLAGNELO; PEREZ; 2015, p. 275).

Outro fator de importância durante a gestão é a alteração dos meios de financiamento da cultura por renúncia fiscal, estabelecida pela Lei n. 14.600, de 29 de dezembro de 2008, que irá atualizar o SEITEC, definindo que as empresas interessadas em realizar contribuições para ações culturais deveriam fazê-lo diretamente ao FUNCULTURAL, o que ocasionou a diminuição da participação da iniciativa privada, que não poderia mais realizar suas estratégias de marketing cultural, associando sua marca aos produtos culturais incentivados (OLIVEIRA, 2007). A gestão dos fundos de cultura no período de governo de Luiz Henrique da Silveira foi marcada por escândalos (como o caso do incentivo dado a um projeto da atriz televisiva Vera Fischer, em detrimento de projetos independentes que pleiteavam o mesmo financiamento), pela mobilização da sociedade civil e da classe artística quanto à falta de transparência nas contas da cultura e pela investigação realizada pelo Tribunal de Contas do Estado (TCE) quanto ao não cumprimento dos critérios estabelecidos pela legislação, apontando como principais irregularidades a falta de análise técnica e a fragilidade na avaliação dos projetos.

Em 2008, foi lançada a primeira edição do Edital Elisabete Anderle de Apoio às Artes e à Cultura, buscando democratizar a distribuição de recursos públicos para o setor cultural, fomentando a produção e a difusão da cultura no Estado. As inscrições foram abertas em 2009, quando 1.428 projetos se inscreveram nas sete áreas abarcadas pelo edital, concorrendo aos 229 prêmios oferecidos. As áreas atendidas pelo projeto eram: artes populares, que foi subdividida nos segmentos folclore, artesanato e arte circense; artes visuais, que visou projetos, obras e bolsas de execução; dança, para a qual foram disponibilizados recursos para produção e para a circulação de espetáculos; Letras, com foco nas publicações e no projeto "Escritor na Escola"; música, na qual a finalidade dos recursos foi a gravação de CDs e DVDs; patrimônio cultural, com o investimento direcionado para os segmentos material e imaterial, museus e acervos; teatro, cujos prêmios foram para circulação, montagem e pesquisa.

Na gestão do governador Luiz Henrique da Silveira ocorreu com maior intensidade a inserção, no estado, das ações desenvolvidas pelo MinC, seja pelos fóruns e conselhos 
organizados na esfera federal, seja pela participação de movimentos sociais no programa Cultura Viva, nos anos de 2004, 2005 e 2007, e, em 2008, no programa Mais Cultura. As gestões dos ministros Gilberto Gil e Juca Ferreira à frente do MinC, entre os anos de 2003 e 2010, trouxeram grandes transformações para o setor, promovendo a descentralização das políticas culturais, o que ocasionou a modificação das relações entre o governo federal, os entes federados e a sociedade civil. A federalização de projetos culturais promovida pelo governo do Partido dos Trabalhadores (PT), por meio de iniciativas como o programa Mais Cultura, as Conferências Nacionais, o Plano Nacional de Cultura e o Sistema Nacional de Cultura, constituiu instrumento de consolidação de uma rede entre agentes de cultura, evitando a concentração estatal nas decisões sobre as ações desenvolvidas e a centralização administrativa recorrente nas políticas culturais produzidas em gestões anteriores. Entretanto, tais políticas nem sempre encontraram reverberação entre os entes federados, nos quais predominavam, por vezes, projetos políticos distintos dos defendidos pelo MinC e pelo plano de governo do PT, como o caso de Santa Catarina.

As ações desenvolvidas pelo governo federal criaram redes de mobilização, gestão, articulação e organização em nível local entre os agentes culturais, possibilitando a inserção de novos sujeitos nas esferas públicas e novas demandas para o Estado, como é possível perceber na Carta de Fraiburgo (2011), escrita durante o I Fórum de Gestores Municipais de Cultura, organizado pela Federação Catarinense de Municípios (FECAM) e o Conselho dos Gestores Municipais de Santa Catarina (CONGESC). Dentre as reivindicações direcionadas ao governo de Santa Catarina e à SOL estavam: a democratização do Conselho Estadual de Cultura e a elaboração do Plano Estadual de Cultura, nos moldes do Plano Nacional de Cultura; a escolha de técnicos capacitados e com experiência em gestão cultural para administrar a área nas SDRs; a busca de soluções legais para o uso dos recursos do FUNCULTURAL, que tinham sido alvo de investigações do Tribunal de Contas do Estado; o apoio à criação de um órgão gestor específico para a cultura, "com status de secretaria de Estado, entendendo que, apenas dessa forma, Santa Catarina estará alinhada à União, por intermédio do Ministério da Cultura, cuja existência considera irreversível no ordenamento institucional do País" (CONSELHO..., 2011, s.p.). 
Segundo Dellagnelo e Perez (2015, p. 278), essa articulação fomentada pelas ações do MinC criou diferenças de posicionamento entre as esferas municipais e estadual em Santa Catarina quanto à construção de políticas culturais alinhadas com o governo federal, causando grande impacto no setor.

A gestão estadual não estava à parte das políticas federais - Santa Catarina foi o primeiro estado a aderir ao Sistema Nacional de Cultura (SNC), em 2010, firmando o Acordo de Cooperação Federativa em 2011 -, apesar de se mostrar reticente quanto à manutenção de sua adesão durante o primeiro ano do governo de Raimundo Colombo (2011-2014), por não se saber se as contrapartidas seriam interessantes para o Estado de Santa Catarina. O SNC foi constituído como mecanismo de gestão e promoção voltado a estimular a integração das políticas públicas para a cultura entre os governos federal, estadual e municipal, garantindo a continuidade das ações mesmo com a alteração dos governos. O acordo, em Santa Catarina, foi renovado em 2011, para o exercício de 2012 (devido à grande pressão popular, como veremos adiante) e por prazo indeterminado em 2013, efetivando o pacto entre estado e União para a implantação de um modelo de gestão das políticas públicas a partir do conceito ampliado de cultura, com vistas a valorizar e fomentar a diversidade das manifestações artísticas e culturais existentes, além de buscar garantir o pleno exercício dos direitos culturais.

Nesse período, não havia ainda no estado uma agenda voltada para instituir parcerias com o MinC, talvez pelo descompasso entre o programa estadual e a ideia de construir uma política pública de cultura que abarcasse as exigências do SNC, que eram a formação do Conselho Estadual de Cultura, do Plano Estadual de Cultura, do Fundo Estadual de Cultura e a estruturação de um órgão exclusivo para os assuntos culturais, demandas recorrentes nos encontros do setor cultural organizados no estado. Para que o debate sobre a necessidade de mudanças no setor tivesse espaço na esfera política, foram cruciais a mobilização da sociedade civil e a adesão ao SNC na gestão de Raimundo Colombo. Apesar de já contar com um fundo de cultura, regulamentado pela legislação referente ao SEITEC, e um Conselho Estadual de Cultura, a instituição de um novo órgão exclusivo para assuntos culturais pelo SNC deveria ser realizada por lei própria, aprovada pela Assembleia Legislativa, e os processos envolvidos na constituição de espaços 
deliberativos como os conselhos e fóruns deveriam ser democráticos, o que não era a realidade de Santa Catarina.

Em Santa Catarina, a base de constituição do Plano Estadual de Cultura foram o PDIL e as metas definidas para o Plano Nacional de Cultura, em conjunto com as contribuições de agentes de cultura coletadas durante fóruns realizados e registradas em documentos como a Carta de Fraiburgo (2011). Em 2013, o Fórum Estadual de Cultura entregou à sociedade o Plano Estadual de Cultura, mas a legislação específica relativa ao Sistema Estadual de Cultura, que regulamentaria o processo, não foi votada na Assembleia Legislativa; 7 e suas instituições, até o momento de escrita deste trabalho, ainda não estavam adequadas às exigências do SNC.

Entre 2011 e 2012, a cidade de Florianópolis foi palco de intensa mobilização da sociedade civil para a cultura, com a realização da Novembrada Cultural e do Ocupa CIC, movimentos organizados por representantes do setor cultural e da classe artística do estado, reivindicando maior transparência nos processos políticos, a adesão ao SNC e o cumprimento do seu cronograma, a revisão da legislação referente aos incentivos culturais, o lançamento de editais públicos e maior democratização nas ações desenvolvidas pela SOL e pela FCC, com respeito às decisões e sugestões realizadas pelo CEC. Pode-se, sobre isso, evocar Benjamin (1985, p. 229), para quem “a história é objeto de uma construção cujo lugar não é o tempo homogêneo e vazio, mas um tempo saturado de "agoras", e esses movimentos atuaram no sentido de explodir o continuum da história das políticas culturais em Santa Catarina, lutando por uma transformação social.

A Novembrada Cultural, nomeada em referência às manifestações populares ocorridas em novembro de 1979 contra a ditadura civil-militar, foi organizada pela Frente em Defesa da Cultura Catarinense e contou com manifestações e eventos culturais em diferentes regiões da cidade. O movimento reivindicava o pagamento de projetos aprovados pelo CEC, a adesão de Santa Catarina ao SNC, a revisão da legislação referente ao FUNCULTURAL e o lançamento de novos editais para o setor cultural. O secretário da

\footnotetext{
7 Em julho de 2017, o secretário da SOL, Leonel Pavan, afirmou que o projeto de lei havia sido encaminhado para a ALESC. (Projeto de lei..., 2017).
} 
SOL na época, César Souza Filho, manteve o diálogo com o movimento e respondeu positivamente às pautas solicitadas. No entanto, como afirmaram os integrantes da Frente de Defesa da Cultura, eram necessárias ações contínuas voltadas para o setor, que seriam conquistadas com a construção de uma política pública democrática para a cultura:

Porém, as expectativas da classe cultural catarinense são anteriores à gestão do Secretário, elas ecoam por décadas e são urgentes. Sendo assim, pedimos compreensão quando enfatizamos que mais do que discursos, a classe cultural de Santa Catarina precisa de ações e, principalmente, que elas sejam contínuas. (FRENTE..., 2011, s.p.)

O movimento Ocupa $\mathrm{CIC}$ ocorreu como desdobramento das reivindicações que não foram plenamente atendidas pela SOL após a Novembrada Cultural. Com intervenções artísticas, apresentações musicais e debates, os manifestantes se mobilizaram no acampamento em frente ao Centro Integrado de Cultura (CIC) entre os dias 23 e 27 de abril de 2012, exigindo um encontro com os responsáveis pela FCC e pela SOL para a entrega da carta de reivindicações assinada por representantes de 131 instituições e associações culturais do estado. Dentre as dez reinvindicações descritas na carta, estava a demanda por maior transparência nos processos administrativos, principalmente naqueles relativos à implantação do Sistema Estadual de Cultura (SEC-SC) e nos trabalhos desenvolvidos pelas instituições: "a transparência das atividades desenvolvidas pela SOL e FCC, com publicização de informações e prestações de contas, além da disponibilização das atas do CEC e publicação do Diário Oficial na internet" (OCUPA CIC, 2012, s.p.). A abertura das arenas políticas para a participação da sociedade civil e a valorização dos agentes culturais nesse processo é uma constante nas reivindicações dos manifestantes, publicadas no blog do movimento ${ }^{8}$ :

Salientamos que essas reivindicações não são recentes, datam pelo menos uma década. São reivindicações que estão na pauta nacional de

\footnotetext{
${ }^{8}$ Em sintonia com movimentos que ocorreram em 2011, como o Occupy Wall Street Nova York e $15 \mathrm{M}$ da Espanha, onde o uso das mídias sociais foi uma arma importante para a mobilização e a difusão dos movimentos. Os administradores do blog (http://ocupa-cic.blogspot.com.br/ - acesso em 02 nov. 2017) nele registraram a trajetória do movimento e divulgaram suas ideias e manifestos.
} 
políticas públicas culturais e muitas delas já se tornaram leis através do Plano Nacional de Cultura. O que procuramos é o alinhamento da política pública estadual com o Plano Nacional de Cultura através de um processo democrático, transparente e participativo, com toda a sociedade civil. (OCUPA CIC, 2012, s.p.)

Ao final dos cinco dias de mobilização, com diversas ações no espaço ocupado, como sessões de cinema, apresentações de teatro, oficinas, palestras e assembleias deliberativas, e também com manifestações de apoio de outros municípios, o movimento chegou ao fim com a promessa de continuidade de luta pela cultura, tendo em vista que, mesmo com o recebimento da carta pelo presidente da FCC, Joceli de Souza, a realização de suas reivindicações ainda não estava garantida.

Os movimentos Novembrada Cultural e Ocupa CIC ocasionaram o embate entre projetos políticos para o setor e sua transformação, reafirmando que as relações entre cultura e política não podem ficar encerradas nos corredores burocráticos do Estado, e que a participação da sociedade civil pode ser fator para a mudança da cultura política conservadora e autoritária que predomina em Santa Catarina. A cultura é política, e seus significados estão inseridos nos processos que redefinem o poder social (ALVAREZ et al, 2006, p. 17).

\section{Considerações finais}

A formação do setor cultural na esfera estadual em Santa Catarina foi perpassada por projetos políticos conservadores. Quando havia consonância entre os projetos políticos federais e estaduais, as políticas instituídas encontraram reverberação nas ações desenvolvidas, como ocorreu no final da década de 1980 no estado. Como não era esse o cenário encontrado durante o início do século XXI, percebemos embates nas gestões estaduais no processo de consolidação do programa Mais Cultura e das políticas fomentadas pelo governo federal do período. A sociedade civil foi um agente relevante na mobilização para a instituição dessas políticas culturais no estado, exercendo pressão e gerando conflitos com o setor cultural estatal, objetivando sua maior democratização. As redes de mobilização fomentadas pelos programas federais foram essenciais na 
articulação desses sujeitos, reunindo aqueles que foram apartados dos tradicionais grupos dominantes da cultura no estado, interessados em ampliar a esfera pública, a publicização dos processos de seleção de projetos e o poder decisório da sociedade na formulação de políticas públicas culturais.

\section{Referências}

ALVAREZ, Sonia E. et al. (Org.). Cultura e política nos movimentos sociais latinoamericanos: novas leituras. Belo Horizonte: UFMG, 2000.

BENJAMIN, Walter. Obras escolhidas. São Paulo: Brasiliense, 1985.

BERSTEIN, Serge. A cultura política. In: RIOUX, Jean-Pierre; SIRINELLI, Jean-François. Para uma história cultural. Lisboa: Estampa, 1998, p. 349-363.

BRUNNER, José Joaquim. Un espejo trizado: ensayos sobre cultura y políticas culturales. Santiago de Chile: FLACSO, 1988.

CARREIRÃO, Yan_Eleições e sistema partidário em Santa Catarina (1945-1979). 1988. 289 f. Dissertação (Mestrado em Sociologia) - Programa de Pós-Graduação em Ciências Sociais, Universidade Federal de Santa Catarina, Florianópolis, 1988.

CONSELHO DOS GESTORES MUNICIPAIS DE SANTA CATARINA - CONGESC (Fraiburgo). Carta de Fraiburgo: Documento defende criação dos Sistemas Municipais e Estadual de Cultura. 2011. Disponível em: http://www.fecam.org.br/noticias/index/ver/codMapaltem/ 74947/codNoticia/372747. Acesso em: 08 out. 2017

DAGNINO, Evelina. Os Movimentos Sociais e a emergência de uma nova cidadania. In: DAGNINO, E. (org). Anos 90: Política e sociedade no Brasil. São Paulo: Brasiliense, 2004, p. $103-115$.

DAGNINO, Evelina. Políticas culturais, democracia e projeto neoliberal. Revista Rio de Janeiro, Rio de Janeiro, n. 15, p. 45-65, jan./abr. 2005.

DAGNINO, Evelina; OLVERA, Alberto J.; PANFICHI, Aldo. A disputa pela construção democrática na América Latina. São Paulo: Paz e Terra; Campinas, SP: Unicamp, 2006.

DE MASI, Domenico. O ócio criativo. Rio de Janeiro: Sextante, 2000.

DELLAGNELO, Eloise Helena Livramento; PEREZ, Felipe Amaral Borges Marcon. Políticas Públicas de Cultura em Santa Catarina no contexto dos programas e ações do governo federal no período entre 2003-2011. In: BARBALHO, Alexandre; et al. Federalismo e políticas culturais no Brasil. Salvador: EDUFBA, 2013. p. 267-288. 
DUWE, Ricardo. Entre a técnica e a tradição: relações e culturas políticas na arena catarinense (1971-1975). 2016. 280 p. Dissertação (Mestrado em História) - Programa de Pós-Graduação em História, Universidade do Estado de Santa Catarina, Florianópolis, 2016.

\section{FRENTE CATARINENSE DE DEFESA DA CULTURA. Carta de Avaliação da Novembrada} Cultural 2011. 30 nov. 2011. Disponível em:

https://novembradacultural.wordpress.com/2011/11/30/avaliaca02011/. Acesso em: 22 nov. 2017.

KLEINÜBING, Vilson; KONDER-REIS, Antônio Carlos. Plano SIM: para viver melhor em Santa Catarina. Florianópolis: 1991.

LENZI, Zuleika Mussi. Novos rumos para a cultura. In: CULTURA. Ano 1, n. o, Setembro/outubro de 1988. Florianópolis; Secretaria da Cultura e do Esporte e Fundação Catarinense de Cultura. Disponível em: www.hemeroteca.ciasc.sc.gov.br/. Acesso em: 27 set. 2017.

LUCA, Tânia Regina de. História dos, nos e por meio dos periódicos. In: BASSANEZI, Carla Pinsky (Org.). Fontes históricas. 2. ed. São Paulo: Contexto, 2006. p. 111-15

MIRANDA, Elflay. Descentralização e territorialização do sistema de planejamento do desenvolvimento em Santa Catarina: uma análise sistêmica do período 2003-2010. 2012. 298 p. Tese (Doutorado em Sociologia Política) - Universidade Federal de Santa Catarina, Florianópolis, 2012.

MOTTA, Rodrigo Patto Sá. Desafios e possibilidades na apropriação de cultura política pela historiografia. In: MOTTA, Rodrigo Patto Sá (org.). Culturas políticas na história: novos estudos. Belo Horizonte, MG: Argvmentvm, 2009. p. 13-39.

MOTTA, Rodrigo Patto Sá. A cultura política comunista. In: NAPOLITANO, Marcos et al (Orgs.). Comunistas brasileiros: cultura política e produção cultural. Belo Horizonte: Editora UFMG, 2013. p. 15-34.

OCUPA CIC (Santa Catarina). Manifesto do OCUPA CIC. 2012. Disponível em: https://ocupacic.wordpress.com/2012/04/25/manifesto-do-ocupa-cic/. Acesso em: 02 nov. 2017.

OLIVEIRA, Rafael Pereira. Políticas culturais e o campo museal em Santa Catarina (19872006). 2007. 169 f. Dissertação (Mestrado em Administração) - Universidade Federal de Santa Catarina, Florianópolis, 2007.

OS PRODUTORES E A RELAÇÃO ESTADO/CULTURA. Cultura, Florianópolis: Secretaria da Cultura e do Esporte, ano 1, n. 0, set./out. 1988. Disponível em: www.hemeroteca.ciasc.sc.gov.br/. Acesso em: 27 set. 2017. 
PROJETO de lei que irá regulamentar o Sistema Estadual de Cultura é encaminhado à Alesc. O Sol Diário. Florianópolis, p. 12. 05 jul. 2017. Disponível em:

<http://osoldiario.clicrbs.com.br/sc/diversao-e-estilo/noticia/2017/07/projeto-de-lei-que-iraregulamentar-o-sistema-estadual-de-cultura-e-encaminhado-a-alesc-9834203.html>.

Acesso em: 12 nov. 2017.

RUBIM, Antonio Albino. Políticas culturais no Brasil: tristes tradições, enormes desafios. In: RUBIM, Antonio Albino. (Org.). Políticas culturais no Brasil. Salvador: Ufba, 2007. p. 1136.

SANTA CATARINA. Lei Complementar $\mathrm{n}^{\circ}$ 243, de 20 de janeiro de 2003 - estabelece nova Estrutura Administrativa do Poder Executivo. Diário Oficial do Estado de Santa Catarina, Florianópolis, n. 17086, 31 jan. 2003.Disponível em:

http://www.portaldoservidor.sc.gov.br/ckfinder/userfiles/

arquivos/LegislacaoCorrelata/Reforma_Administrativa/

2003_Lei_Complementar_N_243,_de_30_de_janeiro_de_2003.pdf. Acesso em: 14 out. 2017.

SANTA CATARINA. Lei n. 13336, de 08 de março de 2005 - institui o Fundo Estadual de Incentivo à Cultura - FUNCULTURAL, o Fundo Estadual de Incentivo ao Turismo FUNTURISMO, e o Fundo Estadual de Incentivo ao Esporte - FUNDESPORTE, no âmbito do Sistema Estadual de Incentivo à Cultura, ao Turismo e ao Esporte - SEITEC, e estabelece outras providências. Diário Oficial do Estado de Santa Catarina, Florianópolis, n. 17.593, 08 mar. 2005. Disponível em:

http://legislacao.sef.sc.gov.br/html/leis/2005/lei_05_13336.htm. Acesso em: 10 set. 2016.

SANTA CATARINA. Lei n. 14600, de 29 de dezembro de 2008 - modifica a estrutura do Sistema Estadual de Incentivo à Cultura, ao Turismo e ao Esporte - SEITEC, altera dispositivos da Lei n. 13.336, de 2005, que institui o FUNCULTURAL, o FUNTURISMO e o FUNDESPORTE e adota outras providências. Diário Oficial do Estado de Santa Catarina. Florianópolis, n. 18.517, 29 dez. 2008. Disponível em:

http://legislacao.sef.sc.gov.br/html/leis/2008/lei_08_14600.htm. Acesso em: 16 out. 2016.

SANTA CATARINA. Lei n. 4086, de 27 de novembro de 1967 - dispõe sobre a Conselho Estadual de Cultura e dá outras providências. Diário Oficial do Estado de Santa Catarina, Florianópolis, n. 8437, 19 dez. 1967. Disponível

em:http://leis.alesc.sc.gov.br/html/1967/4086_1967_Lei.html. Acesso em: 20 nov. 2015.

SANTA CATARINA. Decreto $\mathrm{n}^{\circ} 2080$, de 03 de fevereiro de 2009. Regulamenta a Lei $\mathrm{n}^{\circ}$ 13.792, de 18 de julho de 2006, que dispõe sobre o Plano Estadual da Cultura, do Turismo e do Desporto do Estado de Santa Catarina - PDIL, define diretrizes e critérios relativos aos programas e subprogramas que prevê e estabelece outras providências. Florianópolis, SC, 03 fev. 2009. Disponível em: <http://leisestaduais.com.br/sc/decreto-n-2080-2009santa-catarina-regulamenta-a-lei-n-13792-de-18-de-julho-de-2006-que-dispoe-sobre-oplano-estadual-da-cultura-do-turismo-e-do-desporto-do-estado-de-santa-catarina-pdil- 
define-diretrizes-e-criterios-relativos-aos-programas-e-subprogramas-que-preve-eestabelece-outras-providencias>. Acesso em: 25 nov. 2016.

SANTA CATARINA. Plano Catarinense de Desenvolvimento: SC 2015. Florianópolis: Instituto Celso Ramos, Secretaria de Estado do Planejamento, 2007.

Recebido em: 15/03/2018 Aprovado em: 03/08/2018

Universidade do Estado de Santa Catarina - UDESC Centro de Ciências Humanas e da Educação - FAED

Revista PerCursos Volume 20 - Número 42 - Ano 2019 revistapercursos@gmail.com 